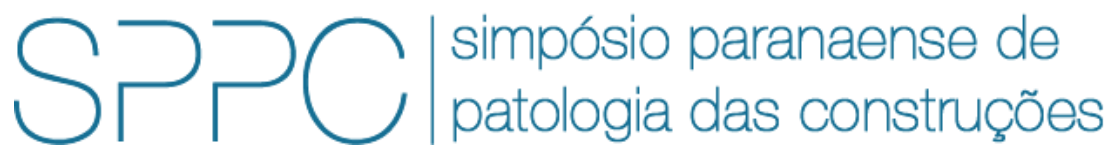

ISSN 2526-7248 artigo 2SPPC1007, pp. 67-80, 2017

\title{
Corrosão acelerada - uma revisão sobre os métodos de ensaio disponíveis
}

\author{
Ana Julia Alves Egg Monteiro'1, Ronaldo A. Medeiros-Junior² \\ ${ }^{1}$ Mestranda, UFPR, anajulia_92@hotmail.com \\ 2 Prof. Dr., UFPR, ronaldodemedeirosjr@yahoo.com.br
}

\begin{abstract}
Resumo: Estruturas de concreto armado estão sujeitas ao aparecimento de manifestações patológicas no decorrer do tempo. A corrosão é um processo de degradação e necessita de acompanhamento contínuo. Tentando prever o comportamento das estruturas frente a essa manifestação, os ensaios de corrosão acelerada são uma ferramenta de auxílio para obter resultados em um menor período de tempo, tendo em vista que o processo natural da corrosão geralmente leva anos para ocorrer. Os ensaios de corrosão acelerada não possuem um padrão dentro da comunidade científica. São realizados através de diversas metodologias, dificultando a comparação dos resultados. O objetivo desse artigo é apresentar e comparar as diferenças dos principais métodos nos ensaios de corrosão acelerada em corpos de prova de concreto armado. Em algumas das metodologias encontradas, foram utilizados corpos de prova submersos em solução salina, para aplicação de corrente elétrica externa, de modo que os cloretos migrem pelo efeito da diferença de potencial. Nesse caso, os autores divergem nas definições das concentrações e dos tipos de sais a serem dissolvidos na solução, e nas intensidades da corrente elétrica. Em outras metodologias são utilizado ciclos de molhagem e secagem na amostra, e também a inserção de sais no concreto fresco. Nesses casos é possível variar a porcentagem de íons cloretos, tempo dos ciclos de molhagem e secagem, e a concentração salina que o corpo de prova é submetido no processo de molhagem. Os ensaios podem se diferenciar pelas características do concreto armado ensaiado como traço, fator a/c e tipo de cimento.
\end{abstract}

Palavras-chave: concreto armado, manifestação patológica, corrosão acelerada, métodos de ensaio

Abstract: Reinforced concrete structures are subject to the appearance of pathological manifestations over time. Corrosion is an aggressive degradation process and requires continuous monitoring. Trying to predict the structure behavior of this manifestation, the accelerated corrosion tests are a support tool to get results in a shorter period of time, considering that the natural process of corrosion usually take years to occur. Accelerated corrosion tests do not have a standard within the scientific community. They are made through various methodologies, making it difficult a possible comparison of results. The purpose of this article is to introduce and compare the differences of the main methods for the testing of accelerated corrosion in reinforced concrete specimens. In some methodologies, test specimens are submerged in a saline solution for applying an external electric current, so that the chlorides migrate by effect of the potential difference. In this case, the authors differ from the definitions of concentrations and types of salts to be dissolved in the solution and intensity of electric current. In others methodologies are used a wetting and drying cycles in the sample and the inclusion of salt in the fresh concrete. In these cases, it is possible to vary the percentage of chloride ions, the time of the wetting and drying cycles, and the salt concentration that the specimen is subjected to wetting process. The tests can be different by the characteristics of the concrete specimen tested as the proportion between materials, $\mathrm{w} / \mathrm{c}$ ratio and type of cement.

Keywords: reinforced concrete, pathological manifestation, accelerated corrosion, test methods 
MONTEIRO, A.J.A.E.; MEDEIROS-JR, R.A., CORROSÃO ACELERADA - UMA REVISÃO SOBRE OS MÉTODOS DE ENSAIO DISPONÍVEIS. $2^{\circ}$ Simpósio Paranaense de Patologia das Construções (20 SPPC), artigo 2SPPC1007, pp. 67-80, 2017. DOI:

\section{Introdução}

Estruturas de concreto armado estão sujeitas ao aparecimento de manifestações patológicas no decorrer do tempo. A corrosão é um processo de degradação agressivo e necessita de acompanhamento contínuo. É um dos fenômenos patológicos mais sérios e de maior repercussão técnico-econômica na área da engenharia civil. O processo afeta criticamente as estruturas civis, prejudicando sua durabilidade e desempenho [1]. Além disso, os elementos de concreto armado podem ser danificados pelo processo de corrosão de maneiras diferentes, que dependem das características estruturais e da agressividade ambiental [2].

A corrosão da estrutura se inicia após a despassivação da armadura, que pode se dar pelo efeito da carbonatação ou pela ação de íons cloretos. A despassivação por carbonatação ocorre através da reação dos produtos de hidratação dissolvidos na água dos poros com o dióxido de carbono do ar, reduzindo $\mathrm{o} \mathrm{pH}$ do concreto, ocasionando a destruição da película passivadora [3]. O efeito de despassivação por íons cloretos tem início quando um valor limite de concentração de cloreto é atingido na interface do concreto com a armadura. Fatores que influenciam nesse valor limite incluem condições atmosféricas como teor de umidade, presença de oxigênio, bem como aspectos relacionados à composição do concreto $[4,5]$.

A ocorrência de manifestações patológicas decorrentes da corrosão de armaduras é muito comum e a comunidade científica tem dedicado uma grande atenção nos últimos anos [2]. Tentando prever o comportamento das estruturas frente a essa manifestação, os ensaios de corrosão acelerada são uma ferramenta de auxílio para obter resultados em um menor período de tempo, tendo em vista que o processo natural da corrosão geralmente leva anos para ocorrer. O efeito da corrosão produzida por meio de ensaios acelerados pode diferir da corrosão natural, em termos de óxidos produzidos, a física da formação, a expansão e liberação de pressão interna devido ao fluxo de óxidos dentro dos microporos e a capilaridade do concreto [2]. Contudo, tendo essas diferenças e as limitações dos ensaios, são ferramentas de auxílio para entender o processo de degradação.

Os ensaios de corrosão acelerada não possuem um padrão dentro da comunidade científica. Apesar do grande número de pesquisas sendo desenvolvidas, elas são realizadas através de diversas metodologias, dificultando a correlação dos resultados $[1]$.

Na literatura, há diversos métodos de ensaio para estudo da corrosão por cloretos. Estes métodos de ensaio acelerado consistem em variações dos tipos de mecanismos de transporte dos íons cloretos do meio externo para o interior do concreto, com exceção a adição de cloretos misturados ao concreto fresco [6]. Angst e Vennesland [6] e Ferreira [5] classificaram e contabilizaram algumas variações de ensaios de corrosão acelerada devido aos cloretos, como absorção e difusão, caracterizado pelo processo de imersão e secagem, difusão pura, através de ensaio de "Ponding Test", migração iônica, pela penetração de cloretos através da aplicação de um campo elétrico, e adicionados em solução, adicionando cloretos na solução sem o uso do campo elétrico, como demonstrados nas Figuras 1 e 2, respectivamente. Para essa compilação foram utilizados artigos publicados em revistas, sendo 39 publicações internacionais e 16 nacionais. 
MONTEIRO, A.J.A.E.; MEDEIROS-JR, R.A., CORROSÃO ACELERADA - UMA REVISÃO SOBRE OS MÉTODOS DE ENSAIO DISPONÍVEIS. $2^{\circ}$ Simpósio Paranaense de Patologia das Construções ( $2^{\circ}$ SPPC), artigo 2SPPC1007, pp. 67-80, 2017. DOI:

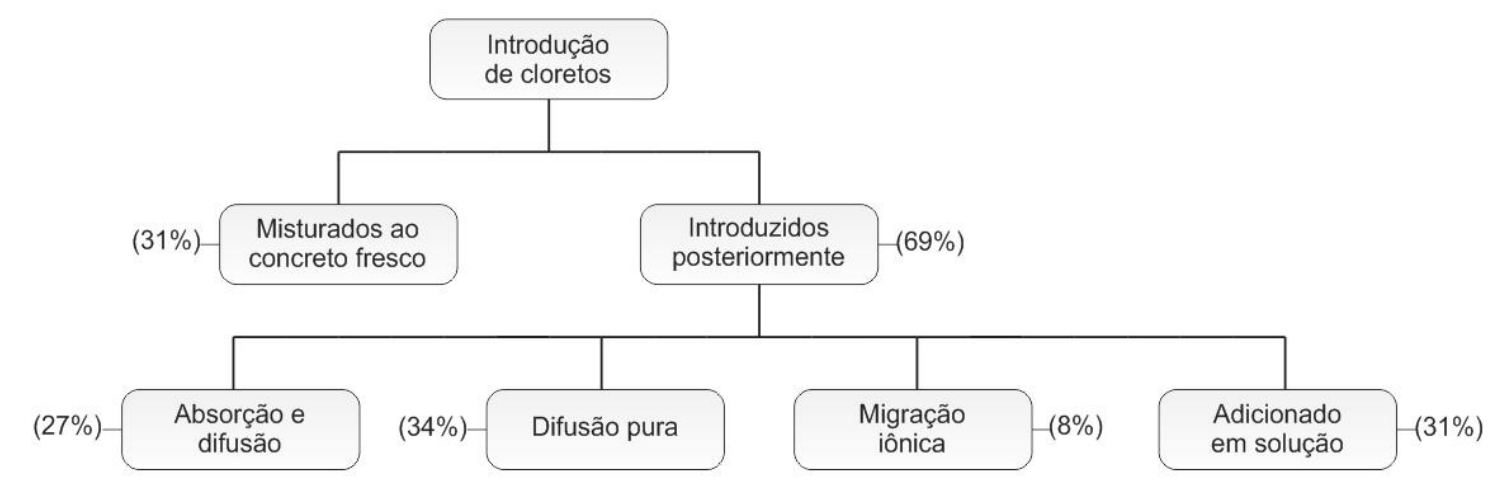

Figura 1: Formas de introdução de cloretos em ensaios acelerados de corrosão Cenário internacional [6].

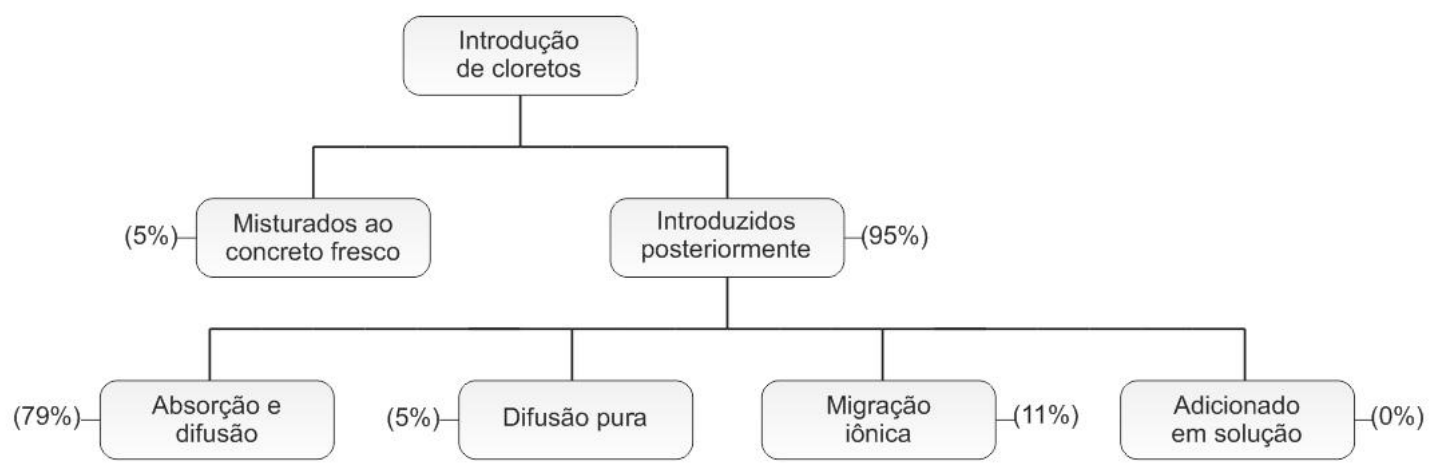

Figura 2: Formas de introdução de cloretos em ensaios acelerados de corrosão Cenário nacional [5].

Conforme as Figuras 1 e 2, há diferentes métodos para realizar ensaios acelerados de corrosão em amostras de concreto. Portanto, o objetivo desse artigo é apresentar e comparar as diferenças dos principais métodos disponíveis para esses ensaios em corpos de prova de concreto armado.

\section{Procedimento de estudo}

O procedimento de estudo deste trabalho consistiu na compilação de alguns artigos com a finalidade de comparar as metodologias de ensaios acelerados de corrosão que foram utilizados. A classificação foi definida através de semelhanças, e foram divididas em: adição de cloretos no concreto fresco; ciclos de molhagem e secagem; migração iônica; e carbonatação acelerada. De modo a descobrir a tendência dos autores atuais para a escolha de ensaios acelerados, foram analisados artigos publicados entre 2013 e 2016 e que utilizam o ensaio de corrosão acelerada para obter resultados. Ao todo foram analisados 14 artigos, sendo um deles feito por autores nacionais e os demais internacionais. Os artigos em sua maioria foram publicados em 2014, mas os anos de publicação variam desde 2013 a 2016, o que pode ser observado na Figura 3. 
MONTEIRO, A.J.A.E.; MEDEIROS-JR, R.A., CORROSÃO ACELERADA - UMA REVISÃO SOBRE OS MÉTODOS DE ENSAIO DISPONÍVEIS. $2^{\circ}$ Simpósio Paranaense de Patologia das Construções ( $2^{\circ}$ SPPC), artigo 2SPPC1007, pp. 67-80, 2017. DOI:

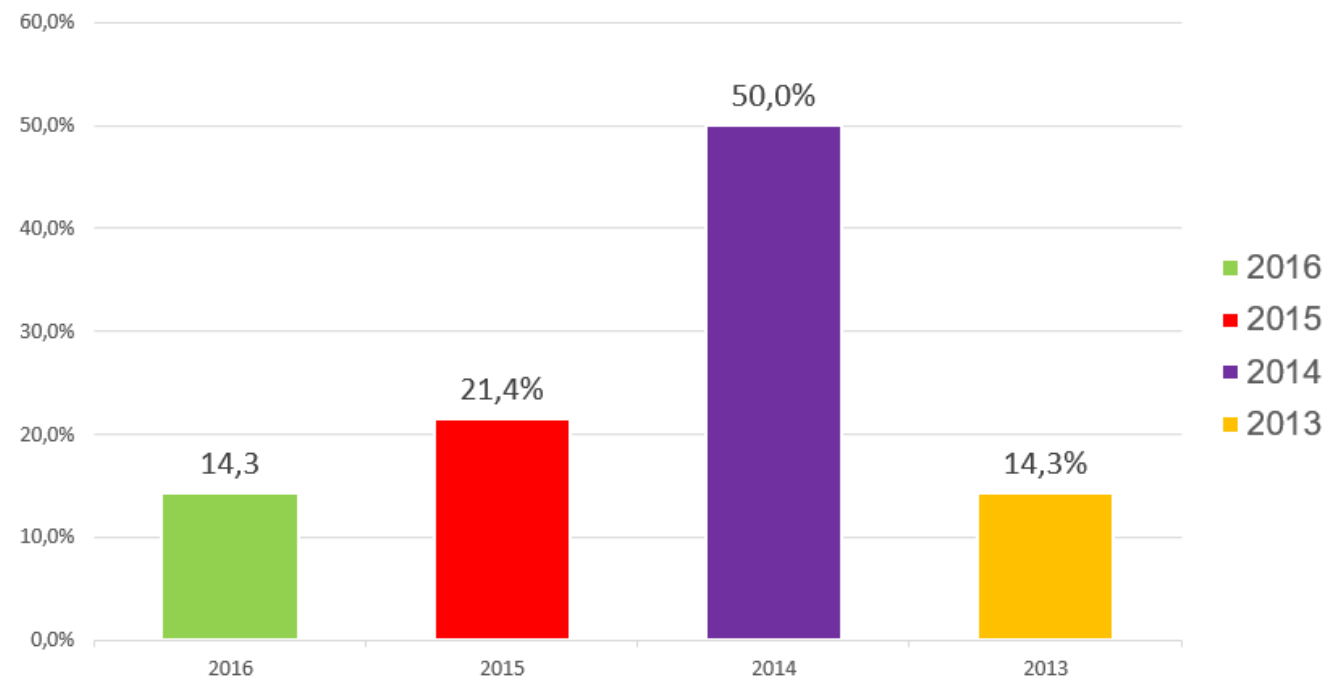

Figura 3: Ano de publicação dos artigos analisados.

\section{Resultados e análises}

\subsection{Primeiras aplicações do ensaio no Brasil}

De acordo com Helene [7], a durabilidade e seu controle no projeto e construção das estruturas de concreto podem ser efetuadas através de 4 procedimentos: com base nas experiências anteriores, com base em ensaios acelerados, através de métodos deterministas e através de métodos estocásticos ou probabilistas. O procedimento com base em ensaios acelerados, segundo Helene [7], foi um método introduzido pelos americanos na norma ASTM E 632 em 1978. No entanto, esse método é de melhor aplicação em estudos de produtos orgânicos e, portanto, de difícil aplicação direta no projeto de estruturas de concreto. Mas, ainda segundo Helene [7], naquela época haviam sido desenvolvidos métodos de ensaios com fundamentos eletroquímicos que poderiam ser utilizados futuramente. Lima [8] desenvolveu uma destas metodologias de ensaio para concreto armado, em que a armadura de um corpo de prova prismático de concreto é conectada ao polo positivo de uma fonte de corrente contínua, e o polo negativo a um eletrodo imerso em solução de cloreto de sódio $0,6 \mathrm{M}$ para ser aplicada uma diferença de potencial de $60 \mathrm{~V}$. Posteriormente, Helene [9] sugeriu impor uma corrente constante no lugar do potencial constante para melhorar o método, ou até mesmo reduzir a diferença de potencial ou da corrente para evitar aquecimento e distorção das reações de corrosão.

\subsection{Primeiras aplicações do ensaio no Brasil}

\subsubsection{Adição de cloretos ao concreto fresco}

Essa é uma metodologia para induzir o processo de corrosão através da adição de determinadas quantidades de íons cloretos ao traço do concreto. Nessa situação, tem-se uma maior homogeneidade de concentração dos íons no concreto em comparação a outros ensaios [5]. Para realização de ensaio de corrosão acelerada, Kashani et al. [10], Mancini et al. [2] e Jin et al. [11] optaram pela adição de cloretos 
no concreto fresco seguido por um ensaio eletroquímico. Jin et al. [11] consideraram em seu estudo a corrosão do concreto armado no meio marinho e solo salino do noroeste da China, e para isso adicionou na água de amassamento, respectivamente, água do mar e um composto $\left(1 \%\right.$ de $\mathrm{NaCl}+0,5$ de $\mathrm{MgSO}_{4}$ em peso de água). Já Mancini et al. [2] adicionaram 3\% NaCl, por peso de cimento, para assegurar o reforço da despassivação e preparar as amostras para a corrosão eletroquímica. Kashani et al. [10], por outro lado, adicionaram $5 \%$ de cloreto de sódio para aumentar a condutividade.

Além disso, Kashani et al. [10] e Mancini et al. [2] optaram por utilizar uma densidade de corrente fixa em seus ensaios eletroquímicos, enquanto Jin et al. [11] utilizaram $30 \mathrm{~V}$ de potencial elétrico. Apesar de Mancini et al. [2] e Kashani et al. [10] terem utilizado como parâmetro a densidade de corrente, os valores a que os corpos de prova foram submetidos foram distintos.

Para a realização do ensaio eletroquímico, Kashani et al. [10] submeteram seus corpos de prova em uma solução com $3 \%$ de $\mathrm{NaCl}$ e uma densidade de corrente de 1,1 a 2,4 mA $/ \mathrm{cm}^{2}$; Mancini et al. [2] fizeram ciclos de molhagem e secagem diários e submeteram seus corpos de prova a uma densidade de corrente de $200 \mu \mathrm{A} / \mathrm{cm}^{2}$. Vale salientar que Jin et al. [11] não mencionam se os corpos de prova estavam úmidos ou submetidos a uma solução, mas os submeteu a um potencial elétrico de $30 \mathrm{~V}$.

Outro fator que variou entre os estudos foi o tempo de duração do ensaio eletroquímico. Kashani et al. [10] variaram a duração entre 5 e 43 dias, Mancini et al. [2] fixaram em 25 dias, e Jin et al. [11] fizeram o ensaio entre 100 e 400h, aproximadamente 4 a 17 dias. A Tabela 1 apresenta um resumo dos ensaios que utilizaram adição de cloretos na massa de concreto. 
MONTEIRO, A.J.A.E.; MEDEIROS-JR, R.A., CORROSÃO ACELERADA - UMA REVISÃO SOBRE OS MÉTODOS DE ENSAIO DISPONÍVEIS. $2^{\circ}$ Simpósio Paranaense de Patologia das Construções ( $2^{\circ}$ SPPC), artigo 2SPPC1007, pp. 67-80, 2017. DOI:

Tabela 1: Resumo dos ensaios que utilizam adição de cloretos na massa de concreto.

\begin{tabular}{|c|c|c|c|c|c|c|c|c|c|}
\hline Método & Autores & Ano & Cura & $a / c$ & $\begin{array}{c}\% \text { adicionado na } \\
\text { massa }\end{array}$ & Solução & $\begin{array}{c}\text { Densidade } \\
\text { de } \\
\text { corrente }\end{array}$ & $\begin{array}{l}\text { Potencial } \\
\text { elétrico }\end{array}$ & $\begin{array}{c}\text { Tempo } \\
\text { total } \\
\text { do } \\
\text { ensaio }\end{array}$ \\
\hline $\begin{array}{c}\text { Mistura } \\
\text { na } \\
\text { massa }\end{array}$ & $\begin{array}{l}\text { Kashani } \\
\text { et al. }\end{array}$ & 2013 & ND & ND & $\begin{array}{l}\text { Adição } 5 \% \text { do } \\
\text { peso de cimento } \\
\text { em cloreto de } \\
\text { sódio }\end{array}$ & $\begin{array}{c}3 \% \\
\text { solução } \\
\mathrm{NaCl}\end{array}$ & $\begin{array}{c}1,1 \mathrm{a} \\
2,4 \mathrm{~mA} / \mathrm{cm}^{2}\end{array}$ & ND & $\begin{array}{l}5 \text { a } 43 \\
\text { dias }\end{array}$ \\
\hline $\begin{array}{c}\text { Adição } \\
\text { na } \\
\text { massa }\end{array}$ & $\begin{array}{l}\text { Mancini } \\
\text { et al. }\end{array}$ & 2014 & ND & ND & $3 \%$ & ND & $\begin{array}{c}200 \\
\mu \mathrm{A} / \mathrm{cm}^{2}\end{array}$ & ND & 25 dias \\
\hline $\begin{array}{c}\text { Adição } \\
\text { na } \\
\text { massa }\end{array}$ & Jin et al. & 2016 & $\begin{array}{c}28 \\
\text { dias }\end{array}$ & 0,34 & $\begin{array}{c}\text { Água }+ \text { água do } \\
\text { mar+ } 1 \% \\
\mathrm{NaCl}+0,5 \% \mathrm{MgSO}_{4} \\
\text { em peso de agua } \\
\text { de amassamento }\end{array}$ & ND & ND & $30 \mathrm{~V}$ & $\begin{array}{c}4 \text { a } 17 \\
\text { dias }\end{array}$ \\
\hline
\end{tabular}

${ }^{*} \mathrm{ND}=$ não disponível

\subsubsection{Ciclos de molhagem e secagem}

Esse ensaio submete os corpos de prova a períodos de molhagem e secagem em solução tanto agressiva como não agressiva, para posterior secagem em ambiente que pode ou não se controlado [5]. Esse método visa simular zona de agressividade de variação de maré e respingo, ou como uma fonte externa de cloretos.

Malheiro et al. [12], Ramezanianpour et al. [13] e Yu et al. [14] escolheram, como ensaio de corrosão acelerada, a realização de ciclos de molhagem e secagem dos corpos de prova. Malheiro et al. [12] e Ramezanianpour et al. [13] avaliaram também o efeito da carbonatação nos corpos de prova, mas nesse subitem só será abordado o ensaio de corrosão acelerada.

Ramezanianpour et al. [13] e Yu et al. [14] não fizeram nenhum preparo prévio no corpo de prova; já Malheiro et al. [12] fez uma pintura com tinta à base epóxi em todas as faces, exceto aquela que se pretendia que houvesse a penetração dos agentes agressivos; dessa forma, os autores simularam uma penetração unidirecional dos íons. O processo de pintura demorou 3 dias, e o de secagem 4 dias.

Os 3 estudos tiveram divergências na definição do período de cura dos corpos de prova e da relação água-cimento. Malheiro et al. [12] utilizaram cura de 28 e 90 dias e um fator a/c de 0,56. Ramezanianpour et al. [13] fizeram uma cura de 7 dias e utilizaram relações a/c de 0,35, 0,40 e 0,45. Por fim, Yu et al. [14] curaram seus corpos de prova por 28 dias e utilizaram $0,40,0,50$ e 0,60 como relação a/c.

Além disso, os autores mencionados no parágrafo anterior não entram num consenso sobre qual solução é a melhor para usar na molhagem dos corpos de prova, nem na quantidade de ciclos de molhagem e secagem ou no tempo total do ensaio. No estudo de Malheiro et al. [12] foram realizadas simulações diferentes de molhagem e secagem. Nos corpos de prova com cura de 28 dias a solução que foi utilizada possui 
MONTEIRO, A.J.A.E.; MEDEIROS-JR, R.A., CORROSÃO ACELERADA - UMA REVISÃO SOBRE OS MÉTODOS DE ENSAIO DISPONÍVEIS. $2^{\circ}$ Simpósio Paranaense de Patologia das Construções ( $2^{\circ}$ SPPC), artigo 2SPPC1007, pp. 67-80, 2017. DOI:

$3,5 \%$ de $\mathrm{NaCl}$, e o período de molhagem é de um dia na solução e 6 dias de secagem, durante 8 ciclos para finalização do ensaio. Nos corpos de prova que ficaram por 90 dias na cura, o tempo de molhagem aumentou para 2 dias, porque os resultados obtidos no ensaio dos corpos de prova de 28 dias de cura foram abaixo do esperado. A concentração da solução é a mesma, e o período de secagem estabelecido foi de 12 dias, finalizando o ensaio em 4 ou 12 ciclos.

O ensaio de Ramezanianpour et al. [13] simulou carbonatação e penetração de íons cloretos simultaneamente. Este subitem dará enfoque somente ao processo de ingresso de cloretos, a carbonatação será discutida em outro subitem deste artigo. Ramezanianpour et al. [13] utilizaram uma solução com $0,3 \%$ de $\mathrm{NaOH}$ e $3 \%$ de $\mathrm{NaCl}$ para um ciclo com duração total de $6 \mathrm{~h}$, simulando uma zona de variação de maré.

Yu et al. [14] utilizou uma solução com concentração de $5 \%$ de $\mathrm{NaCl}$ durante 50 minutos para a molhagem do corpo de prova que também estava submetido a um vento de $3 \mathrm{~m} / \mathrm{s}$, para simular a atmosfera de ambiente marinho, e o restante do tempo é de secagem, até totalizar 12 ou 30 h de estudo.

Portanto, observa-se que a duração dos ensaios é bastante variável de um estudo para o outro. Os ensaios de molhagem e secagem tiveram períodos de duração desde 12 a 30h [14], até 168 dias [12].

A Tabela 2 compara os diferentes ensaios de molhagem e secagem contidos nesse artigo.

Tabela 2: Resumo dos ensaios que utilizam molhagem e secagem.

\begin{tabular}{|c|c|c|c|c|c|c|c|c|c|}
\hline Método & Autores & Ano & $\begin{array}{l}\text { Preparo } \\
\text { prévio }\end{array}$ & $\underset{\mathbf{a}}{\text { Cur }}$ & $a / c$ & $\begin{array}{l}\text { Molha- } \\
\text { gem }\end{array}$ & $\begin{array}{c}\text { Secage } \\
\mathrm{m}\end{array}$ & $\begin{array}{c}\text { Ciclo } \\
\mathbf{s}\end{array}$ & $\begin{array}{c}\text { Tempo } \\
\text { total } \\
\text { do } \\
\text { ensaio } \\
\end{array}$ \\
\hline \multirow[b]{2}{*}{$\begin{array}{l}\text { Molha- } \\
\text { gem e } \\
\text { secagem }\end{array}$} & \multirow[b]{2}{*}{ Malheiro et al. } & \multirow[b]{2}{*}{2014} & \multirow{2}{*}{\begin{tabular}{|} 
Pintura \\
base \\
epóxi nas \\
faces \\
exceto a \\
que terá \\
a pene- \\
tração
\end{tabular}} & $\begin{array}{c}28 \\
\text { dias }\end{array}$ & \multirow[b]{2}{*}{0,56} & $\begin{array}{l}1 \mathrm{dia} \\
3,5 \% \\
\mathrm{NaCl} \\
\end{array}$ & 6 dias & 8 & 56 dias \\
\hline & & & & $\begin{array}{c}90 \\
\text { dias }\end{array}$ & & $\begin{array}{l}2 \text { dias } \\
3,5 \%\end{array}$ & 12 lab & $\begin{array}{c}4 \text { ou } \\
12\end{array}$ & $\begin{array}{l}56 \text { a } \\
168 \\
\text { dias }\end{array}$ \\
\hline $\begin{array}{l}\text { Molha- } \\
\text { gem e } \\
\text { secagem }\end{array}$ & $\begin{array}{l}\text { Ramezanianpour } \\
\text { et al. }\end{array}$ & 2014 & ND & $\begin{array}{c}7 \\
\text { dias }\end{array}$ & $\begin{array}{c}0,35 \\
0,40 \text { e } \\
0,45\end{array}$ & \multicolumn{2}{|c|}{$\begin{array}{c}0,3 \% \mathrm{NaOH} 3 \% \\
\quad \mathrm{NaCl} 6 \mathrm{~h}\end{array}$} & ND & $\begin{array}{l}28 \text { e } 90 \\
\text { dias }\end{array}$ \\
\hline $\begin{array}{l}\text { Molha- } \\
\text { gem e } \\
\text { secagem }\end{array}$ & Yu et al. & 2015 & ND & $\begin{array}{c}28 \\
\text { dias }\end{array}$ & $\begin{array}{c}0,40 \\
0,50 \mathrm{e} \\
0,60\end{array}$ & $\begin{array}{c}5 \% \\
\mathrm{NaCl} \\
50 \mathrm{~min}\end{array}$ & $\begin{array}{l}\text { Restante } \\
\text { até } 30 \mathrm{~h} \\
\text { ou } 12 \mathrm{~h}\end{array}$ & 1 & $\begin{array}{l}12 \mathrm{~h} \mathrm{e} \\
30 \mathrm{~h}\end{array}$ \\
\hline
\end{tabular}

${ }^{*} \mathrm{ND}=$ não disponível

\subsubsection{Migração iônica}

A corrosão das armaduras do concreto armado é um processo eletroquímico que pode ser quantificado pela medição da intensidade da corrente no concreto [15]. Os ensaios de migração iônica através de cargas elétricas, ou eletromigração, tem como característica a aplicação de uma corrente ou potencial elétrico para acelerar o 
MONTEIRO, A.J.A.E.; MEDEIROS-JR, R.A., CORROSÃO ACELERADA - UMA REVISÃO SOBRE OS MÉTODOS DE ENSAIO DISPONÍVEIS. $2^{\circ}$ Simpósio Paranaense de Patologia das Construções ( $2^{\circ}$ SPPC), artigo 2SPPC1007, pp. 67-80, 2017. DOI:

processo de corrosão. Pereira et al. [16], Erdem [17], Ortega et al. [15], Duffó et al. [18], Pei et al. [19] e Otieno et al. [20-21] utilizaram esse conceito para acelerar a corrosão em seus corpos de prova. Para preparação dos corpos de prova, foi utilizado um período de cura de 28 dias [15,16,18,19,20,21], ou de 27 dias [17]. Ortega et al. [15] classificaram seus corpos de prova de acordo com o tipo de cura em 4 categorias que podem ser acessadas em Ortega et al. [15].

Ortega et al. [15], Duffó et al. [18], Pei et al. [19] fixaram valores da relação águacimento, enquanto Erdem [17], Pereira et al. [16] e Otieno et al. [20-21] fixaram valores da relação água-aglomerante. Os valores adotados tanto para relação a/c quanto para a relação a/a diferem bastante entre si. Duffó et al. [18] utilizaram relação 0,50 e 0,60, Ortega et al. [15] utilizaram 0,60 e Pei et al. [19] 0,32. Para a relação a/a foram adotados valores de 0,31, considerando a adição de cinza volante [17], 0,40, 0,50 e 0,60 para Pereira et al. [16], e 0,40 e 0,55 para os estudos de Otieno et al. [20-21].

Alguns autores fizeram um preparo nos corpos de prova antes de submetê-los aos ensaios de eletromigração. Duffó et al. [18] deixaram os corpos de prova submersos em um container por $24 \mathrm{~h}$ para umidecê-los. Pei et al. [19] submeteram seus corpos de prova a 3 dias de molhagem e 4 dias de secagem em uma solução com $3 \%$ de $\mathrm{NaCl}$, e Otieno et al. [20-21], também submeteram a 3 dias de molhagem e 4 de secagem, porém em uma solução de concentração de $5 \%$.

No ensaio de eletromigração de Duffó et al. [18], foi utilizada uma densidade de corrente de 50 a $750 \mu \mathrm{A} / \mathrm{cm}^{2}$; já Erdem [17] escolheram usar $30 \mathrm{~V}$ de potencial elétrico com os corpos de prova imersos em uma solução com $10 \%$ de $\mathrm{NaCl}$. Ortega et al. [15] utilizou uma densidade de corrente elétrica de $100 \mathrm{~mA} / \mathrm{cm}^{3}$. Pereira et al. [16] usaram uma solução de concentração $35 \mathrm{~g} / \mathrm{l}$ de $\mathrm{NaCl}$ para submeter seus corpos de prova a uma densidade de corrente de $500 \mu \mathrm{A} / \mathrm{cm}^{2}$. Uma solução de $3 \%$ de $\mathrm{NaCl}$ foi utilizado por Pei et al. [19]. Por fim Otieno et al. [20-21] utilizaram uma densidade de corrente de $0,35 \mu \mathrm{A} / \mathrm{cm}^{2}$, sendo que os corpos de prova estavam submetidos a um pequeno reservatório com solução de $5 \%$ de $\mathrm{NaCl}$.

Quanto à duração dos ensaios de eletromigração, há variação conforme os autores. Duffó et al. [18] e Ortega et al. [15] tiveram 15 dias de duração dos seus ensaios. Erdem [17] realizou seu ensaio em $72 \mathrm{~h}$ com um intervalo de $24 \mathrm{~h}$. Pereira et al. [16] consideraram 20 dias de ensaio eletroquímico, mais 7 dias para secagem total dos corpos de prova, totalizando 27 dias de ensaio. Pei et al. [19] fizeram seus ensaios em 6 ciclos de 7 dias, totalizando 42, e Otieno et al. [20-21] realizaram os ensaios em 90 dias.

A Tabela 3 apresenta o resumo dos dados dos ensaios de eletromigração. 
MONTEIRO, A.J.A.E.; MEDEIROS-JR, R.A., CORROSÃO ACELERADA - UMA REVISÃO SOBRE OS MÉTODOS DE ENSAIO DISPONÍVEIS. $2^{\circ}$ Simpósio Paranaense de Patologia das Construções ( $2^{\circ}$ SPPC), artigo 2SPPC1007, pp. 67-80, 2017. DOI:

Tabela 3: Resumo dos ensaios que utilizam eletromigração.

\begin{tabular}{|c|c|c|c|c|c|c|c|c|c|c|}
\hline Método & Autores & Ano & $\begin{array}{l}\text { Preparo } \\
\text { prévio }\end{array}$ & $\begin{array}{c}\text { Cur } \\
\mathbf{a}\end{array}$ & $a / c$ & $\mathbf{a} / \mathbf{a}$ & $\begin{array}{c}\text { Soluçã } \\
0\end{array}$ & $\begin{array}{c}\text { Densida } \\
\text {-de de } \\
\text { Corrent } \\
\text { e }\end{array}$ & $\begin{array}{l}\text { Poten- } \\
\text { cial } \\
\text { elétrico }\end{array}$ & $\begin{array}{c}\text { Tempo } \\
\text { total do } \\
\text { ensaio }\end{array}$ \\
\hline $\begin{array}{l}\text { Eletromi } \\
\text {-gração }\end{array}$ & $\begin{array}{l}\text { Pereira } \\
\text { et al. }\end{array}$ & 2013 & ND & $\begin{array}{c}28 \\
\text { dias }\end{array}$ & ND & $\begin{array}{c}0,40 \\
0,50 \\
e \\
0,60\end{array}$ & $\begin{array}{l}35 \mathrm{~g} / \mathrm{l} \\
\mathrm{NaCl}\end{array}$ & $\begin{array}{c}500 \\
\mu \mathrm{A} / \mathrm{cm}^{2}\end{array}$ & ND & $\begin{array}{c}20 \text { dias } \\
+7 \text { dias } \\
\text { secagem }\end{array}$ \\
\hline $\begin{array}{l}\text { Eletromi } \\
\text {-gração }\end{array}$ & Erdem & 2014 & ND & $\begin{array}{c}27 \\
\text { dias }\end{array}$ & ND & 0,31 & $\begin{array}{l}\text { Soluçã } \\
010 \% \\
\mathrm{NaCl}\end{array}$ & ND & $30 \mathrm{~V}$ & $\begin{array}{l}72 \mathrm{~h} \text { com } \\
\text { um } \\
\text { intervalo } \\
\text { de } 24 \mathrm{~h}\end{array}$ \\
\hline $\begin{array}{l}\text { Eletromi } \\
\text {-gração }\end{array}$ & $\begin{array}{c}\text { Ortega et } \\
\text { al. }\end{array}$ & 2014 & ND & $\begin{array}{l}28 \\
\text { dias }\end{array}$ & 0,6 & ND & ND & $\begin{array}{c}100 \\
\mathrm{~mA} / \mathrm{cm}^{2}\end{array}$ & ND & 100 dias \\
\hline $\begin{array}{l}\text { Eletromi } \\
\text {-gração }\end{array}$ & $\begin{array}{c}\text { Duffó et } \\
\text { al. }\end{array}$ & 2015 & $\begin{array}{c}\text { Container } \\
\text { com agua } \\
\text { por } 24 \mathrm{~h} \\
\text { para } \\
\text { umidecer }\end{array}$ & $\begin{array}{c}28 \\
\text { dias }\end{array}$ & $\begin{array}{c}0,50 \\
e \\
0,60\end{array}$ & ND & ND & $\begin{array}{c}50 \\
\mu \mathrm{A} / \mathrm{cm}^{2} \mathrm{a} \\
750 \\
\mu \mathrm{A} / \mathrm{cm}^{2}\end{array}$ & ND & 15 dias \\
\hline $\begin{array}{l}\text { Eletromi } \\
\text {-gração }\end{array}$ & Pei et al. & 2015 & $\begin{array}{c}3 \text { dias } \\
\text { molhagem } \\
4 \text { dias } \\
\text { secagem } \\
(3 \% \mathrm{NaCl})\end{array}$ & $\begin{array}{l}28 \\
\text { dias }\end{array}$ & 0,32 & ND & $\begin{array}{c}\text { Soluçã } \\
\text { o 3\% } \\
\mathrm{NaCl}\end{array}$ & ND & ND & 6 ciclos \\
\hline $\begin{array}{l}\text { Eletromi } \\
\text {-gração }\end{array}$ & $\begin{array}{l}\text { Otieno, } \\
\mathrm{H} \text {. et al. }\end{array}$ & 2016 & $\begin{array}{c}3 \text { dias } \\
\text { molhagem } \\
\text { (5\% NaCl } \\
\text { solução), } 4 \\
\text { dias } \\
\text { secagem }\end{array}$ & $\begin{array}{l}28 \\
\text { dias }\end{array}$ & ND & $\begin{array}{c}0,40 \\
e \\
0,55\end{array}$ & $\begin{array}{c}\text { Reserv } \\
\text { a-tório } \\
\text { com } \\
\text { solução } \\
5 \% \\
\mathrm{NaCl}\end{array}$ & $\begin{array}{c}0,35 \\
\mu \mathrm{A} / \mathrm{cm}^{2}\end{array}$ & ND & 90 dias \\
\hline
\end{tabular}

${ }^{\star} \mathrm{ND}=$ não disponível

\subsubsection{Carbonatação acelerada}

Badar et al. [22] e Duprat et al. [23] realizaram em seu estudo a carbonatação acelerada. Para isso tiveram que definir os níveis de $\mathrm{CO}_{2}$ que seriam utilizados no ensaio assim como o tempo de duração do teste. Duprat et al. [23] utilizaram em seus experimentos um corpo de prova com relação a/c 0,72, e os submeteu a uma cura de 7 dias; depois da cura, preparou os corpos de prova por 28 dias em uma câmara com variáveis controladas. Badar et al. [22] utilizaram uma relação a/a de 0,5 para um corpo de prova que curou por $72 \mathrm{~h}$. Neste estudo, foi definido um nível de $5 \%$ de $\mathrm{CO}_{2}$ para um tempo de ensaio de 450 dias. Já Duprat et al. [23] utilizaram um nível de dióxido de carbono mais alto, $50 \%$, para um menor tempo de ensaio, 5 a 10 dias. A Tabela 4 resume os fatores dos ensaios de carbonatação. 
MONTEIRO, A.J.A.E.; MEDEIROS-JR, R.A., CORROSÃO ACELERADA - UMA REVISÃO SOBRE OS MÉTODOS DE ENSAIO DISPONÍVEIS. $2^{\circ}$ Simpósio Paranaense de Patologia das Construções ( $2^{\circ}$ SPPC), artigo 2SPPC1007, pp. 67-80, 2017. DOI:

Tabela 4: Resumo dos ensaios que utilizam carbonatação acelerada.

\begin{tabular}{|c|c|c|c|c|c|c|c|c|}
\hline \multicolumn{1}{|c|}{ Método } & Autores & Ano & Preparo prévio & Cura & a/c & a/a & $\begin{array}{c}\text { Níveis } \\
\text { de CO2 }\end{array}$ & $\begin{array}{c}\text { Tempo } \\
\text { total do } \\
\text { ensaio }\end{array}$ \\
\hline Carbonatação & Badar et al. & 2014 & ND & $72 \mathrm{~h}$ & ND & 0,5 & $\begin{array}{c}5 \% \pm \\
0,3 \%\end{array}$ & 450 dias \\
\hline Carbonatação & $\begin{array}{c}\text { Duprat et } \\
\text { al. }\end{array}$ & 2014 & $\begin{array}{c}28 \text { dias em } \\
\text { câmara com } 65 \% \\
\text { umidade relativa } \\
\text { e } 20 \text { graus celsius }\end{array}$ & 7 dias & 0,72 & ND & $50 \%$ & $\begin{array}{c}5 \text { a } 10 \\
\text { dias }\end{array}$ \\
\hline
\end{tabular}

${ }^{*} \mathrm{ND}=$ não disponível

\subsubsection{Discussões gerais}

Segundo os resultados deste artigo, pode-se observar que há uma tendência de preferência pelos autores por determinado método de corrosão acelerada . Dentre os artigos estudados, $29 \%$ foram realizados somente através do ensaio de eletromigração, 14\% uniram os ensaios de eletromigração com os de molhagem e secagem, $21 \%$ optaram somente pelo ensaio de molhagem e secagem do corpo de prova, $21 \%$ adicionaram soluções de $\mathrm{NaCl}$ na água de amassamento do concreto, e $14 \%$ seguiram com a carbonatação, como mostra a Figura 4. Contudo, ressalta-se que esses valores podem variar bastante, dependendo dos artigos aos quais os autores tem acesso para realizar a copilação.

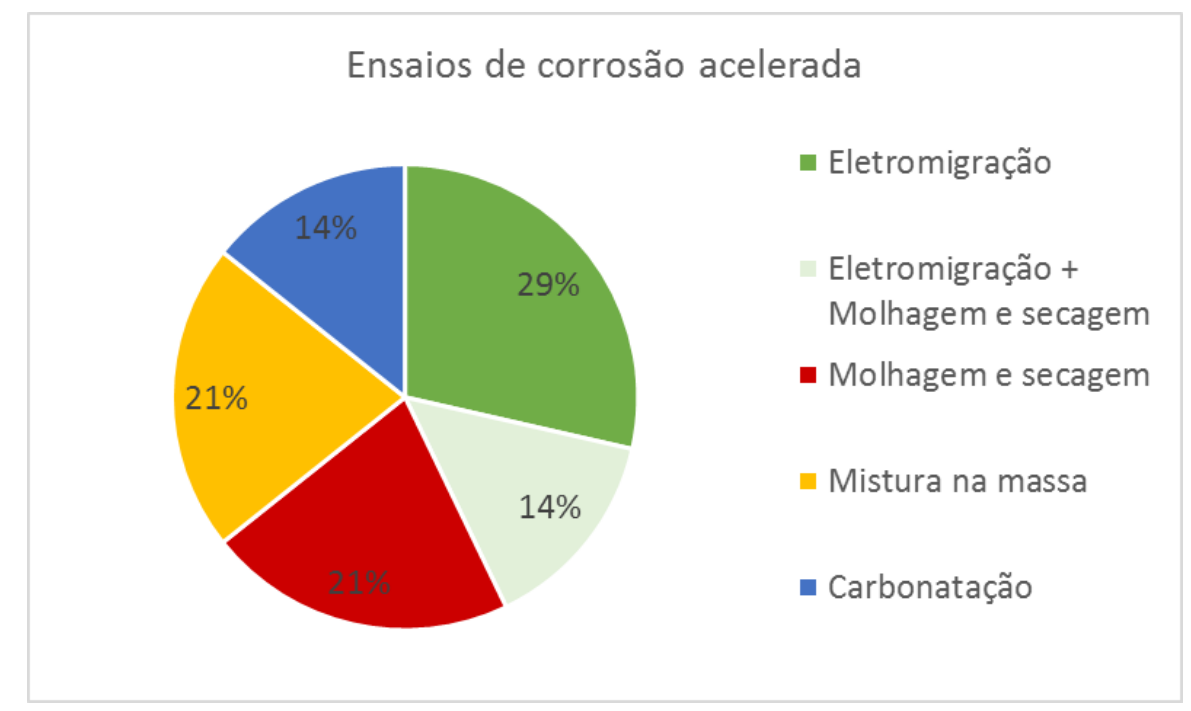

Figura 4: Ensaios de corrosão acelerada.

Dentre todos os artigos, $64 \%$ deles utilizam de alguma forma, o ensaio de eletromigração (Figura 5), e 36\% utilizam o ensaio de molhagem e secagem (Figura 6) para a obteção de resultados. 
MONTEIRO, A.J.A.E.; MEDEIROS-JR, R.A., CORROSÃO ACELERADA - UMA REVISÃO SOBRE OS MÉTODOS DE ENSAIO DISPONÍVEIS. $2^{\circ}$ Simpósio Paranaense de Patologia das Construções (20 SPPC), artigo 2SPPC1007, pp. 67-80, 2017. DOI:

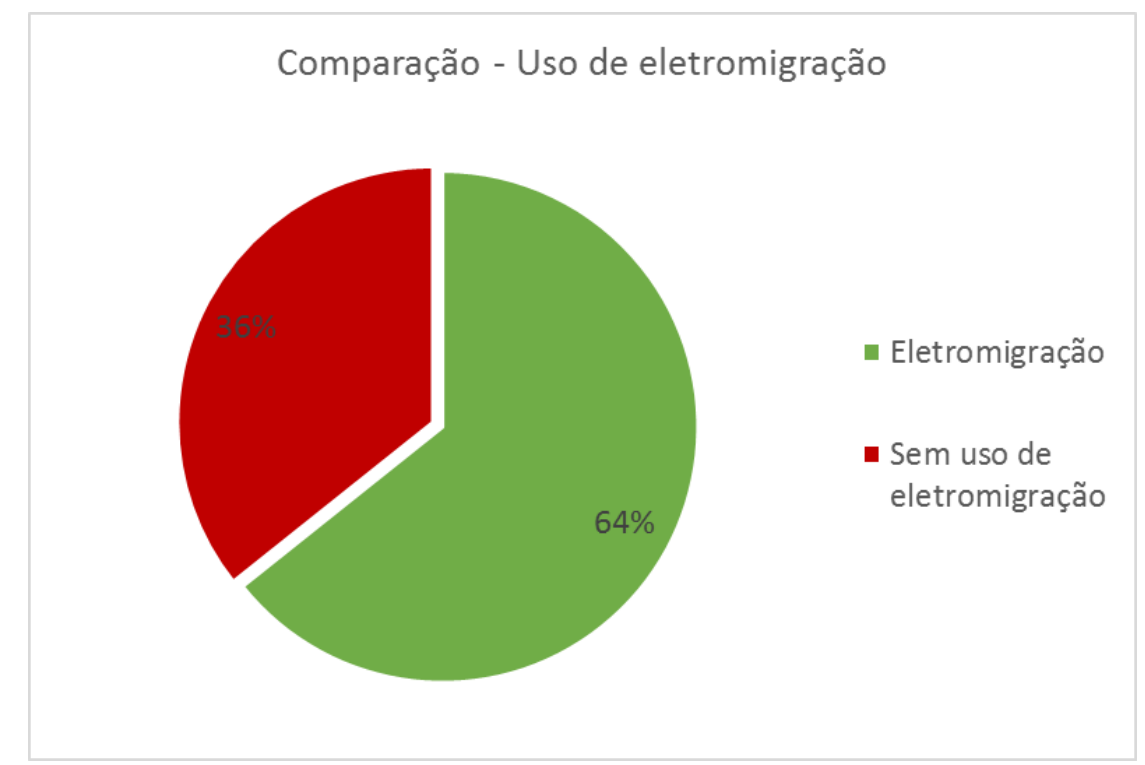

Figura 5: Uso do ensaio de eletromigração, conforme amostra de artigos analisada.

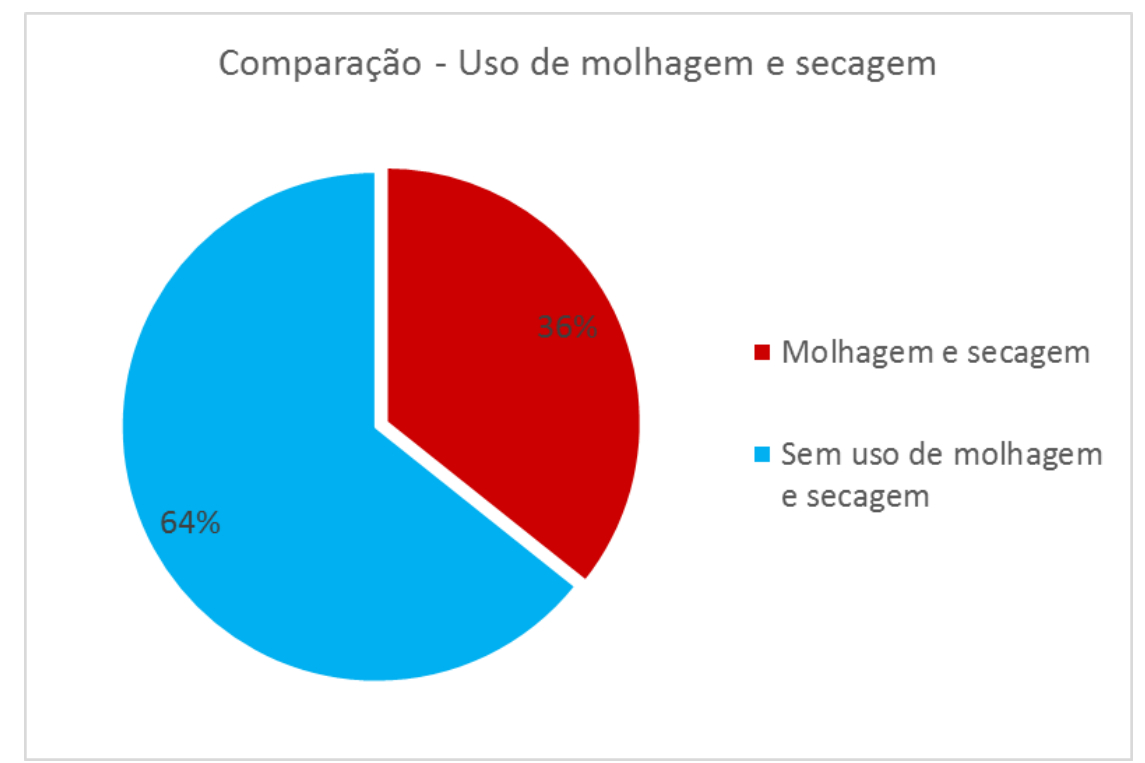

Figura 6: Uso do ensaio de molhagem e secagem, conforme amostra de artigos analisada.

Quanto aos métodos de ensaios analisados, os que utilizam cloretos adicionados na massa de concreto têm como vantagem a maior homogeneidade de íons cloreto no corpo de prova, quando comparados à outros ensaios.

Os corpos de prova que foram submetidos à ciclos de molhagem e secagem possuem como grande vantagem a simulação da variação de maré, importante para a simulação acelerada principalmente de estruturas offshore. Tem como desvantagem a necessidade de maior tempo de ensaio em comparação com outros métodos, e o acompanhamento para correta execução dos ciclos.

Os de eletromigração tem como vantagem a rapidez no aparecimento dos resultados, conforme a carga ou corrente elétrica aplicada. Como desvantagem pode-se citar a diferença com as condições reais de exposição, pela aplicação de uma maior diferença de potencial que a real para acelerar o processo. 
MONTEIRO, A.J.A.E.; MEDEIROS-JR, R.A., CORROSÃO ACELERADA - UMA REVISÃO SOBRE OS MÉTODOS DE ENSAIO DISPONÍVEIS. $2^{\circ}$ Simpósio Paranaense de Patologia das Construções ( $2^{\circ}$ SPPC), artigo 2SPPC1007, pp. 67-80, 2017. DOI:

Os ensaios de carbonatação acelerada possuem grande variação nos níveis de $\mathrm{CO}_{2}$ e consequentemente variação no tempo total do ensaio, entre os artigos estudados. Tem como característica a simulação da perda da passivação da armadura, favorecendo a corrosão generalizada, enquanto os demais ensaios favorecem a corrosão por pites.

\section{Conclusões}

Através desse estudo percebe-se a tendência dos autores a utilizarem a eletromigração, associado ou não com outro método, como escolha para realização dos ensaios acelerados de corrosão. É importante ressaltar que essas conclusões estão baseadas no espaço amostral de 14 artigos utilizados para essa pesquisa. Uma possível justificativa para essa escolha é a facilidade de realização do ensaio, sem a necessidade de realizar adições ainda no concreto fresco, ou o trabalho de submeter o corpo de prova à molhagem e secagem em períodos de tempo determinados. De uma maneira geral, ensaios que envolvem a eletromigração tendem a ser mais rápidos e de menor custo em comparação aos que não se utilizam desse conceito. $A$ escolha de aplicar um potencial ou corrente elétrica para acelerar a corrosão vai de encontro com o fato da corrosão de estruturas de concreto armado apresentar reações eletroquímicas. Mas fica a cargo do autor determinar qual ensaio representará melhor o efeito desejado, levando em consideração o tempo, os equipamentos, soluções e componentes químicos necessários.

\section{Agradecimentos}

Agradecemos à Universidade Federal do Paraná e ao Programa de Pós Graduação em Engenharia de Construção Civil pela disponibilidade de recursos essenciais para a formulação desse artigo.

\section{Referências}

[1] TORRES, A. S.; GUIMARÃES, D.; SILVA FILHO, L. C. P. D. Avaliação do método CAIM de corrosão acelerada em diferentes condições de ensaio. In: /I Seminário e Workshop em Engenharia Oceânica, Rio Grande, 2006.

[2] MANCINI, G.; TONDOLO, F.; IULIANO, L.; MINETOLA, P. Local reinforcing bar damage in r.c. members due to accelerated corrosion and loading. Construction and Building Materials, v. 69, p. 116-123, 2014.

[3] CHI, J. M., HUANG, R., \& YANG, C. Effects of carbonation on mechanical properties and durability of concrete using accelerated testing method. Journal of Marine Science and Technology, v 70, p. 14-20, 2002.

[4] MORENO, J. D.; BONILLA, M.; ADAM, J. M.; BORRACHERO, V.; SORIANO, L. Determining corrosion levels in the reinforcement rebars of buildings in coastal areas. A case study in the Mediterranean coastline. Construction and Building Materials, v. 100, p. 11-21, 2015.

[5] FERREIRA, P. R. R. Análise da indução da corrosão por cloretos em concretos armados com adição de resíduo de tijolo moído a partir de ensaios acelerados. 
MONTEIRO, A.J.A.E.; MEDEIROS-JR, R.A., CORROSÃO ACELERADA - UMA REVISÃO SOBRE OS MÉTODOS DE ENSAIO DISPONÍVEIS. $2^{\circ}$ Simpósio Paranaense de Patologia das Construções ( $2^{\circ}$ SPPC), artigo 2SPPC1007, pp. 67-80, 2017. DOI:

Dissertação (mestrado), Universidade Federal de Pernambuco, Recife, Pernambuco, 2015.

[6] ANGST, U. M.; VENNESLAND, Ø. Critical chloride content in reinforced concrete - State of the art. Concrete Repair, Rehabilitation and Retrofitting II. Taylor \& Francis Group, p. 311- 317, London, 2009.

[7] HELENE, P. R. L. Introdução da durabilidade no projeto das estruturas de concreto. Ambiente Construído, São Paulo, v. 1, n. 2, p.45-57, 1997.

[8] LIMA, M.G. Influência dos componentes do concreto na corrosão das armaduras. Dissertação (Mestrado). Universidade Federal do Rio Grande do Sul, Porto Alegre, Rio Grande do Sul, 1989.

[9] HELENE, P. R. L. Contribuição ao estudo da corrosão em armaduras de concreto armado. 1993. $231 \mathrm{f}$. Tese (Doutorado) - Departamento de Engenharia de Construção Civil, Universidade de São Paulo, São Paulo, 1993.

[10] KASHANI, M. M.; CREWE, A. J.; ALEXANDER, N. A. Nonlinear stress-strain behaviour of corrosion-damaged reinforcing bars including inelastic buckling. Engineering Structures, v. 48, p.417-429, 2013.

[11] JIN, Z.; ZHAO, X.; ZHAO, T.; YANG L. Interaction between compressive load and corrosive-ion attack on reinforced concrete with accelerated potentiostatic corrosion. Construction and Building Materials, v. 113, p.805-814, 2016.

[12] MALHEIRO, R; CAMÕES, A.; MEIRA, G.; FERREIRA, R. M.; REIS, R. Durabilidade do betão tendo em conta a ação combinada da carbonatação e dos iões cloreto. $1^{\circ}$ Encontro Luso-brasileiro de Degradação em Estruturas de Concreto Armado, Salvador, p.213-224, 2014.

[13] RAMEZANIANPOUR, A. A.; GHAHARI, S. A.; ESMAEILI, M. Effect of combined carbonation and chloride ion ingress by an accelerated test method on microscopic and mechanical properties of concrete. Construction and Building Materials, v. 58, p.138-146, 2014.

[14] YU, Z.; CHEN, Y.; LIU, P.; WANG W. Accelerated simulation of chloride ingress into concrete under drying-wetting alternation condition chloride environment. Construction and Building Materials, v. 93, p.205-213, 2015.

[15] ORTEGA, N. F.; ROBLES, S. I. Assessment of Residual Life of concrete structures affected by reinforcement corrosion. Hbrc Journal, In press corrected proof, 2014.

[16] PEREIRA, E.; RESENDE, A.; MEDEIROS, M. H. F.; MENEGHETTI L.C. Ensaio acelerado por cloretos: efeito da sílica ativa, relação água/aglomerante e espessura de cobrimento do concreto. Revista Ibracon de Estruturas e Materiais, v. 6, n. 4, p.561-581, 2013.

[17] ERDEM, S. X-ray computed tomography and fractal analysis for the evaluation of segregation resistance, strength response and accelerated corrosion behaviour of self-compacting lightweight concrete. Construction and Building Materials, v. 61, p.10-17, 2014.

[18] DUFFÓ, G.; GAILLARD, N.; MARISCOTTI, M.; RUFFOLO, M. Application of gamma-ray radiography and gravimetric measurements after accelerated 
MONTEIRO, A.J.A.E.; MEDEIROS-JR, R.A., CORROSÃO ACELERADA - UMA REVISÃO SOBRE OS MÉTODOS DE ENSAIO DISPONÍVEIS. $2^{\circ}$ Simpósio Paranaense de Patologia das Construções (20 SPPC), artigo 2SPPC1007, pp. 67-80, 2017. DOI:

corrosion tests of steel embedded in mortar. Cement and Concrete Research, v. 74, p.1-9, 2015.

[19] PEI, H.; LI, Z.; ZHANG, J.; WANG Q. Performance investigations of reinforced magnesium phosphate concrete beams under accelerated corrosion conditions by multi techniques. Construction and Building Materials, v. 93, p.989-994, 2015.

[20] OTIENO, M.; BEUSHAUSEN, H.; ALEXANDER, M. Chloride-induced corrosion of steel in cracked concrete - Part I: Experimental studies under accelerated and natural marine environments. Cement and Concrete Research, v. 79, p.373-385, 2016.

[21] OTIENO, M.; BEUSHAUSEN, H.; ALEXANDER, M. Chloride-induced corrosion of steel in cracked concrete-Part II: Corrosion rate prediction models. Cement and Concrete Research, v. 79, p.386-394, 2016.

[22] BADAR, M. S.; KUPWADE-PATIL, K.; BERNAL, S. A.; PROVIS, J. L.; ALLOUCHE, E. N. Corrosion of steel bars induced by accelerated carbonation in low and high calcium fly ash geopolymer concretes. Construction and Building Materials, v. 61, p.79-89, 2014.

[23] DUPRAT, F.; VU, N.T.; SELLIER, A. Accelerated carbonation tests for the probabilistic prediction of the durability of concrete structures. Construction and Building Materials, v. 66, p. 597-605, 2014. 